\section{Eduardo San José Vázquez}

Doctor por la Universidad de Oviedo, con la tesis Recuperaciones narrativas del siglo XVIII en la narrativa hispanoamericana del siglo XX. Ilustración y modernidad en el Caribe. Es autor de las monografías La memoria posible: «El sueño de la historia», de Jorge Edwards. Ilustración y transición democrática en Chile (Universidad de Oviedo, 2006) y Las luces del siglo (Universidad de Alicante, en prensa). Ha publicado trabajos sobre Alejo Carpentier, Abel Posse, Antonio Benítez Rojo y Edgardo Rodríguez Juliá, entre otros. Actualmente, es investigador posdoctoral en la Universidad de Alicante. Es crítico literario en varias publicaciones periódicas.

1

Reinaldo Arenas, El mundo alucinante. Una novela de aventuras, Barcelona, Tusquets, 2001 [1969]. En adelante, citaré por esta edición, entre paréntesis y en el texto.
Utopía y progreso en El mundo alucinante, de Reinaldo Arenas: Fray Servando y el tiempo histórico EDUARDO SAN JOSÉ VÁZQUEZ

\title{
UTOPÍA Y PROGRESO EN EL MUNDO ALUCINANTE, DE REINALDO ARENAS: FRAY SERVANDO Y EL TIEMPO HISTÓRICO
}

EDUARDO SAN JOSÉ VÁZQUEZ

\begin{abstract}
Aunque con veinte y cuatro años de persecución he adquirido el talento de pintar monstruos, el discurso hará ver que no hago aquí sino copiar los originales.
\end{abstract}

(Fray Servando Teresa de Mier, Memorias)

Las novelas de Reinaldo Arenas han sido consideradas con frecuencia como «ejercicios» $\mathrm{o}$ «juegos» postmodernos. Su estilo neobarroco, el lúdico despliegue de la ironía y la parodia, las estructuras narrativas complejizantes, la abundancia de elementos paratextuales que deshacen la ilusión del artificio mimético, la alteración de la causalidad histórica y su general reflexión sobre la escritura desvelarían, de este modo, la crítica antihistórica del autor cubano. Ha sido común, en este sentido, estudiar la obra de Arenas como ejemplo de una aporía histórica postmoderna, contraponiéndola con toda intención a la narrativa de Alejo Carpentier; una oposición en la que, no en vano, al propio Arenas le agradó contemplar su obra en numerosas ocasiones.

Las interpretaciones postmodernas de la obra de Arenas pueden tener su parte de razones en apreciar en ella aspectos puntuales de una nueva (o parcialmente nueva) estética narrativa, concebida como mimesis desde la precisa negación de un objeto de la imitación. Asimismo, no es descabellado suponer que, a partir del carácter recesivo y escéptico de su percepción de la realidad histórica, tal estética pueda asimilarse, al igual que buena parte de la ficción postmoderna, con posiciones conservadoras alineadas contra una opción política como la que en su contexto puede representar la Revolución Cubana. Sin embargo, es preciso revisar esta interpretación postmodernizante de la obra areniana, en busca de una lectura más aquilatada.

Un caso de la trayectoria literaria del autor cubano destaca especialmente y es ilustrativo de la tendencia crítica apuntada. Así, el hecho de que una de las novelas más conocidas y celebradas de Reinaldo Arenas, El mundo alucinante $(1969)^{1}$, recupere el siglo XVIII, a través de la figura del fraile regiomontano Servando Teresa de Mier, ha favorecido especialmente que se haya automatizado y generalizado un orden de interpretaciones. Dicha lectura trata de descubrir en esta novela dieciochesca una crítica maximalista hacia la modernidad ilustrada, tomando en cuenta el siglo en que característicamente se plantearon algunas nociones como el racionalismo empírico, el progreso histórico o una filosofía de la Historia de valores emancipatorios. Ha sido moneda corriente entre la crítica suponer que el siglo XVIII resulta aquí un pretexto para refutar la modernidad, sobre todo al hacer que la estructura narrativa desmienta en la práctica la noción de progreso temporal, así como a través de su aparente irreverencia mimética. No obstante, un análisis más detenido permite descubrir que el propósito de Reinaldo Arenas en esta novela cae lejos de dicha intención, y que, al contrario, El mundo alucinante es toda una ponderación del progreso histórico tal como fue formulado en el siglo 
de las Luces, sustrayendo dicho concepto de las versiones más restrictivas de la utopía.

\section{AUTORÍA Y ORÍGENES: LA DISPER- SIÓN DE LA VERDAD HISTÓRICA}

Al desconcierto crítico provocado por la publicación de una novela histórica irrealista como El mundo alucinante respondieron varios críticos con una valoración más reposada. Uno de los primeros en hacer una lectura capaz de determinar el valor de la novela y guiar futuros estudios fue Emir Rodríguez Monegal ${ }^{2}$. A partir de los años setenta, el crítico uruguayo, quien para Arenas era «la persona que mejor había interpretado todos mis libros» ${ }^{3}$, comienza a apreciar la crítica dialéctica que se inscribe en la novela, más allá de cierta gratuidad vanguardista en la que podía haberse leído inicialmente. Monegal daba sentido a esa crítica dialéctica en su refutación de la linealidad cronológica, en el cuestionamiento de la referencialidad o en la sistemática contradicción interna de las designaciones literales, mediante la cual la narración desdice lo previamente afirmado. Así, son varios los capítulos de la novela que aparecen repetidos en su alusión numérica, en concreto los dos primeros, que narran la infancia y la salida del protagonista de Monterrey, y el séptimo, que describe las consecuencias del sermón de fray Servando sobre la Virgen de Guadalupe (1794). De este modo, aparecen tres "Capítulo I», titulados «De cómo transcurre mi infancia en Monterrey, junto con otras cosas que también transcurren», «De tu infancia en Monterrey, junto con otras cosas que también ocurren» y «De cómo pasó su infancia en Monterrey, junto con otras cosas que también pasaron». El Capítulo II vuelve a reiterarse: «De mi salida de Monterrey», «De la salida de Monterrey» $\mathrm{y}$ «De tu salida de Monterrey». Los tres capítulos VII aparecen titulados «De las consecuencias del sermón», «De la consecuencia del sermón»y, de nuevo, «De la consecuencia del sermón».

En estas tres series, bajo las tres personas gramaticales, aparecen distintas versiones en conflicto, sin que pueda privilegiarse ninguna de ellas entre las opciones simultáneas y desjerarquizadas que narran, cada una, los orígenes de fray Servando, su inserción en el tiempo histórico y las consecuencias de la lectura del sermón sobre la Virgen de Guadalupe. En muchas ocasiones, la divergencia significante se produce en el interior de un simple párrafo. Ya desde el inicio del primero de los capítulos I se lee: «Venimos del corojal. No venimos del corojal. Yo y las dos Josefas venimos del corojal. Vengo solo del corojal y ya se está haciendo de noche. Aquí se hace de noche antes de que amanezca» (p. 27). Para Alicia Borinsky4, la imposibilidad de elegir "pone entre paréntesis la noción de progresso narrativo», algo que Monegal interpreta en clave política como «otro golpe mortal a la escuela de pensamiento «progresista» de los regímenes que se auto-proclaman socialistas»5. En la misma lógica, la alternancia de las tres personas gramaticales que caracteriza la reiteración numérica de los capítulos, que Emil Volek ha caracterizado expresivamente como un "chachachá epistemológico y narrativo» ${ }^{6}$, impide la instauración de una perspectiva narradora única y contradice las implicaciones teóricas asociadas a la misma. Además de en estos tres capítulos, la proliferación gramatical se repite en el interior de varios de los capítulos singulares, como comienza sucediendo en el Capítulo III, ordenado en sendas partes correspondientes a las tres personas del verbo.

Borinsky, en cuyas interpretaciones precursoras reconoce apoyarse Monegal ${ }^{7}$, considera que este recurso nace de una crítica a las nociones de autor y de orígenes, partiendo de la teoría de la escritura como (re)lectura y del autor como epígono que se deduce del cuento de Borges «Pierre Menard, autor del Quijote» (Ficciones, 1944). Al existir tres capítulos I como inicio de la obra, con contenidos semejantes pero disparejos, $\mathrm{y}$ al hacer éstos referencia, además, a la infancia de Fray Servando, la novela desmiente el concepto de orígenes. Esto, por añadidura, destruye la ilusión de linealidad cronológica y de sustancialismo histórico. Pero, lo que es más importante para esta autora, la dispersión gramatical obedecería al rechazo de la unidad y la identidad del sujeto y de la noción romántica de autor. Esto anularía el previsible intento de una impostación autobiográfica de Arenas a través del padre Mier.

La elección de los capítulos triplicados es significativa. Como apunta Borinsky, el Capítulo I establecería la noción de orígenes, que así se ve desmentida. El Capítulo II, que narra la salida de Monterrey del joven Servando, sería el que diera inicio al tiempo histórico en la novela, dejando atrás
2

Emir Rodríguez Monegal, «El mundo laberíntico de Reinaldo Arenas», en Julio E. Hernández Miyares y Perla Rozencraig (comps.), Reinaldo Arenas: alucinaciones, fantasía y realidad, Glenview, Scott, Foresman / Montesinos, 1990, pp. 5-13.

Este trabajo es una refundición de estudios anteriores del propio Monegal desde 1977 hasta 1981. La relación de los mismos figura al final del artículo.

3

Reinaldo Arenas, Antes que anochezca. Autobiografía, Barcelona, Tusquets, 1992, p. 334.

4

Alicia Borinsky, "Re-escribir y escribir: Arenas, Menard, Borges, Cervantes, Fray Servando», $R e$ vista Iberoamericana, 92-93:41 (1975), pp. 605-616.

Rodríguez Monegal, op. cit., p. 8.

Emil Volek, «La carnavalización y la alegoría en El mundo alucinante, de Reinaldo Arenas", Revista Iberoamericana, 130131:52 (1985), p. 129.

7

Rodríguez Monegal, op. cit., p. 7.

Utopía y progreso en $E l$ mundo alucinante, de Reinaldo Arenas: Fray Servando y el tiempo histórico EDUARDO SAN JOSÉ VÁZQUEZ 


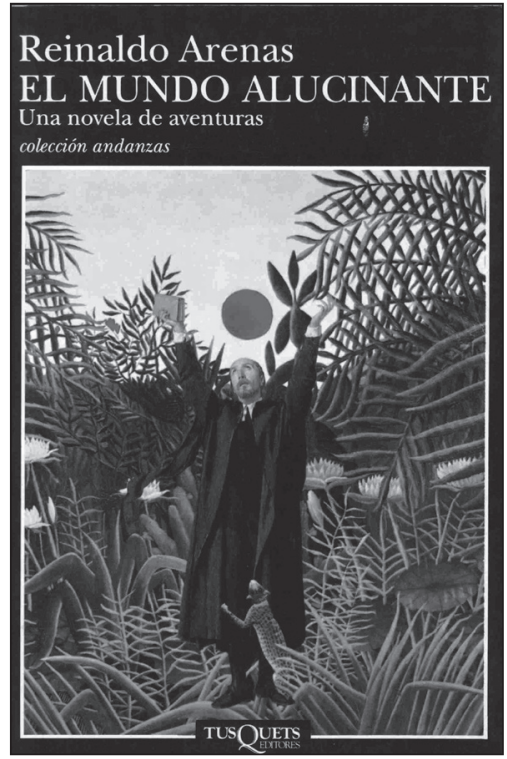

Portada de El mundo alucinante. Borinsky, op. cit., p. 612

Michel Foucault, El orden del discurso, Barcelona, Tusquets, 1973 , p. 16.

Utopía y progreso en El mundo alucinante, de Reinaldo Arenas: Fray Servando y el tiempo histórico EDUARDO SAN JOSÉ VÁZQUEZ el ahistoricismo de la infancia y atisbándose el inicio de una posible épica en su primer viaje a la capital novohispana. La dispersión de sentido provocada por la divergencia gramatical y por las contradicciones internas hace que la novela niegue a partir de aquí la idea misma de Historia. En consecuencia, el Capítulo VII, donde se describen los efectos causados por la lectura del sermón de Guadalupe, adelanta a su vez una teoría de la recepción, por la cual las consecuencias de su sermón no se podrían reducir a una única explicación. Además, el capítulo muestra una posición central, al ser el que narra el comienzo de la odisea represiva de fray Servando desde la primera prisión en su celda, a la conmutación de la pena de muerte a cambio del destierro. El descentramiento de este episodio, que es el que comienza a situar a fray Servando en la Historia, es, por esto, una forma de advertir que la lectura de su emblema histórico debe ser necesariamente controvertida y polémica.

\section{LA HISTORIA, DESDE LOS MÁRGE- NES DE LA HISTORIA}

Más allá del recurso descentrador de este «juego pronominal», como lo llama Borins$\mathrm{ky}^{8}$, la crítica dialéctica de la obra comienza en los elementos paratextuales que preceden la fábula o se sitúan en sus márgenes. En estos fragmentos se vierten algunas opiniones de Reinaldo Arenas sobre el concepto de Historia y sobre el uso de la documentación histórica que ha manejado para componer la novela. El efecto de dispersión de la verdad histórica se refuerza entonces en elementos como los distintos prólogos y encabezamientos de la novela, las notas de carácter bibliográfico a pie de página o el epílogo consignando las últimas noticias de fray Servando, que recuerdan desde el comienzo y a cada paso la tramoya diegética del discurso historicista. De este modo, la supuesta objetividad de la acción histórica se apoya y se prolonga en la instancia subjetiva del historiador. Así, los mismos recursos que para el discurso histórico implican una justificación positiva, en particular los elementos que remiten a fuentes bibliográficas o las declaraciones de autoridad más o menos veladas de prólogos y noticias sobre el autor, sirven para recordar la presencia determinante del historiador en cuanto se narra, que además no es aquí sino una sucesión delirante de hechos.

Este recurso paródico hace que, al aplicarse a contenidos absurdos o recurrir a notas bibliográficas apócrifas, la obra enfatice la importancia de los recursos de sugestión y de creación de una voz de autoridad en el discurso histórico. Foucault considera que estos recursos institucionales de sugestión son, en realidad, una "coacción», por la que sociedades ritualizadas y restrictivas se apropian del discurso. Así, considera Foucault, «la verdad se desplazó del acto [...] de enunciación hacia el enunciado mismo»". A través de recursos de este tipo, la verdad histórica se muestra en última instancia dependiente de las tres máximas de la poética aristotélica: la necesidad, la coherencia y la verosimilitud, además de un conjunto de decisiones retóricas que se vinculan al mandato de un decoro poético, como la economía narrativa, la suspensión del interés de los lectores, el diseño arquetípico de los personajes y de las acciones así como la justicia poética de ciertos desenlaces.

De este modo, El mundo alucinante aparece encabezada por la dedicatoria a Camila Henríquez Ureña y Virgilio Piñera, por su «honradez intelectual», homenaje que en su contexto inmediato constituía una innegable declaración de intenciones políticas contra la Revolución institucionalizada en Cuba. A ésta le siguen dos epígrafes extraídos del Libro $\mathrm{X}$ de Los Mártires y de la Obra general sobre la historia de los mexicanos, de Cristóbal del Castillo, a través de las que Arenas refuerza el carácter autobiográfico («Y yo también he sido desgarrado por las espinas de ese desierto») y la intemporalidad fatal del sufrimiento histórico («...de modo que andaréis atemorizados; en pago de vuestro valor andaréis venciendo y andaréis destruyendo»-p. 13-). El siguiente epígrafe, firmado con las iniciales «R.A.» a modo de una «Advertencia del autor», avanza la presentación genérica de la obra y de sus nociones historiográficas: «Ésta es la vida de fray Servando Teresa de Mier, tal como fue, tal como pudo haber sido, tal como a mí me hubiese gustado que hubiera sido. Más que una novela histórica o biográfica pretende ser, simplemente, una novela» (p. 15). Se observa que la triple simetría de la frase da lugar a tres conceptos diferentes de géneros ocupados de la Historia, de los cuales el orden de enunciación parece privilegiar el último: la historia positivista («tal como fue»), la aristotélica de la ficción histórica 
clásica («tal como pudo haber sido») y la netamente ficcional, que refuerza el sentido de El mundo alucinante con el subtítulo original de la obra: Una novela de aventuras. Reinaldo Arenas se quejaba de que, aun después de la reedición supervisada de la novela, muchos editores habían decidido prescindir del subtítulo, ignorando así la visión irónica y crítica que proyectaba sobre sus referentes históricos ${ }^{10}$.

Tras los distintos epígrafes, la edición original, publicada fuera de Cuba (en México) en 1969, incluía una carta a fray Servando, sin título, a la que a partir de 1980, con el escritor ya exiliado, se le antepone una introducción titulada «Fray Servando, víctima infatigable», firmada en Caracas el 13 de julio del mismo 1980. En este texto, Arenas se pronuncia explícitamente sobre la idea de Historia que anima El mundo alucinante. Es la ocasión de que el autor se exprese en términos críticos contra la idea de Historia y de realismo, al mismo tiempo que declara su ficción dentro de un doble proyecto que no se puede catalogar, por cierto, sino como historicista: una restitución de la figura de fray Servando en la Gran Historia americana y, a través de ella, una textualización autobiográfica.

Arenas señala que comenzó su novela con la idea de recoger, a través de figuras como la de fray Servando y la del cubano José María Heredia, con quien el dominico se encuentra al final de la novela, «el ciclo casi mítico del hombre americano» (p. 17). Éste no sería sino el destierro y la búsqueda de «lo imposible (su patria)» (p. 18). Arenas aclara que «la Historia no certifica si se llegaron a conocer», si bien «todo indica» (p. 17) que coincidieron en sus últimos días en el Palacio Presidencial mexicano. El encuentro entre estos dos personajes, «que la historia «oficial», como la mayoría de los instantes importantes, no registra» (p. 18), haría evidente que el destino del auténtico revolucionario americano habría sido subsistir a estructuras de poder de tipo absolutista y colonial, y que el exilio ha sido asimismo la característica de los primeros héroes nacionales, cuyo oscurecimiento completaría más tarde el discurso histórico, ocultando la significación real y precisa de sus figuras históricas:

Por eso siempre he desconfiado de lo «histórico», de ese dato «minucioso y preciso». Porque, ¿qué cosa es en fin la Historia? [...]. Los impulsos, los motivos, las secretas percepciones que instan (hacen) a un hombre no aparecen, no pueden aparecer recogidos por la
Historia, así como, aun bajo el quirófano, no se captará jamás el sentimiento de dolor del hombre adolorido [...]. Por eso, más que en la Historia busco en el tiempo (p. 19).

Éstas son ideas que se repiten en la novela, con interferencias evidentes entre el texto y el paratexto. Por ejemplo, se lee: «¡Cuántas ideas!...Y sin embargo, pensó, [...] las mejores ideas son precisamente las que nunca logro llevar al papel, porque al hacerlo pierden la magia de lo imaginado» (p.

72). Tras su refutación historiográfica, la introducción arremete contra la noción de causalidad y la concepción lineal del tiempo, para criticar a través de ella la estética realista desde una intención política: «Pero últimamente no sólo tenemos (padecemos) realismo sino que contamos hasta con un realismo socialista, de modo que la realidad ya no sólo es vista desde un ángulo, sino desde un ángulo político» (p. 20). Con la misma intención, critica el reduccionismo, en unos términos que recuerdan a los del Funes borgeano ${ }^{11}$ : «No me cansaré de descubrir que el árbol de la seis de la mañana no es éste de las doce del día, ni aquél, cuyo halo nos consuela al anochecer» (p. 20). Al final, promete encontrar la «verdadera» dimensión histórica de su protagonista: «Y es en ese plano, en el de víctima inconsolable e incansable de la Historia, del tiempo, donde nuestro amado fray Servando logra su verdadera ubicación» (p. 21).

Inmediatamente después, la carta fechada en julio de 1966 que Arenas encabeza con un «Querido Servando», precediendo al cuerpo de la novela, incide en las mismas razones. En primer lugar, explica cómo ha encontrado la noticia de la existencia de fray Servando, «desde que te descubrí, en un renglón de una pésima historia de la literatura mexicana» (p. 23), y lo frustrante de las investigaciones históricas con las que pretendió acercarse mejor a su figura. Después de haber ido a embajadas, a casas de cultura, a museos, «que, desde luego, nada sabían de tu existencia» (p. 23), Arenas concluye que «lo que más útil me ha resultado para llegar a conocerte y amarte, no fueron las abrumadoras enciclopedias, siempre demasiado exactas, ni los terribles libros de ensayo, siempre demasiado inexactos. Lo más útil fue descubrir que tú y yo somos la
10

Véase Jesús J. Barquet, «Del gato Félix al sentimiento trágico de la vida» (entrevista a Reinaldo Arenas), en Ottmar Ette (ed.), La escritura de la memoria. Reinaldo Arenas: Textos, estudios y documentación, Frankfurt am Main / Madrid, Vervuert / Iberoamericana, p. 67.

11

«Éste, no lo olvidemos, era casi incapaz de ideas generales, platónicas. No sólo le costaba comprender que el símbolo genérico "perro» abarcara tantos individuos dispares [...]; le molestaba que el perro de las tres y catorce (visto de perfil) tuviera el mismo nombre que el perro de las tres y cuarto (visto de frente)", Jorge Luis Borges, "Funes e memorioso", Ficciones, Madrid, Anagrama, 1995, p. 134

Utopía y progreso en El mundo alucinante, de Reinaldo Arenas: Fray Servando y el tiempo histórico EDUARDO SAN JOSÉ VÁZQUEZ 
13

Jean-François Lyotard, La condición postmoderna. Informe sobre el saber, Madrid, Cátedra, 1988.

\section{4}

Jean Baudrillard, Cultura y simulacro, Barcelona, Kairós, 1984; El crimen perfecto, Barcelona, Anagrama, 1996.

15

Fernando Moreno, «La historia recurrente y los nuevos cronistas de Indias. (Sobre una modalidad de la novela hispanoamericana actual)», Scriptura, 8/9 (1992), pp. 151-157.

Utopía y progreso en El mundo alucinante, de Reinaldo Arenas: Fray Servando y el tiempo histórico EDUARDO SAN JOSÉ VÁZQUEZ misma persona» (p. 23). El último párrafo deja claro el sentido de restitución histórica de la novela:

No aparecerás en este libro mío (y tuyo) como un hombre inmaculado, con los estandartes característicos de la pureza evangélica, ni como el héroe intachable que sería incapaz de equivocarse, o de sentir alguna vez deseos de morirse. Estás, querido Servando, como lo que eres: una de las figuras más importantes (y desgraciadamente casi desconocida) de la historia literaria y política de América (p. 24).

Recapitulando la crítica discursiva vertida por Arenas en estos márgenes paratextuales, que se incorporan como parte misma de la novela prolongando e interfiriendo con sus interpretaciones posibles, es necesario resaltar que fray Servando aparece como una víctima del discurso histórico tradicional. Esto, unido a la crítica general a la noción de Historia, podría impulsar a considerar una lectura de $E l$ mundo alucinante como un mero comentario historiográfico, y las prisiones sucesivas del dominico, en busca de una imposible plenitud existencial, serían símbolos de las prisiones dialécticas de la norma historiográfica como discurso autoritativo, tal como subraya la presencia en las primeras páginas del rígido maestro español de las primeras letras del niño Servando: «iCondenado él!, que cogió la vara de membrillo y me la hizo astillas en la espalda nada más que porque yo le hacía tres rabos a la «o» y él dice que no hay que hacerle ninguno» (p. 27); maestro que le causará, asimismo, su primera "prisión", al encerrarlo en el servicio (p. 28). Esto se reforzaría con algunas opiniones sobre el discurso histórico vertidas por Arenas en varias entrevistas ${ }^{12}$.

Este rango de observaciones bastaría para avalar una lectura postmoderna de esta novela, situándola sobre la muerte de los grandes relatos diagnosticada en 1979 por Jean-François Lyotard ${ }^{13}$, o, en sus concepciones más rigoristas, de la mano de Jean Baudrillard ${ }^{14}$, sobre la imposibilidad de testificar una realidad recreada ya en su puro simulacro. Suponiendo tal idealismo extremo en la obra de Arenas, cumpliría la definición dada por Fernando Moreno ${ }^{15}$ a la nueva novela histórica, como una narrativa que ha dejado de ser «histórica» para pasar a ser «historiográfica»: ha relegado la Historia para pasar a ocuparse de sus métodos, sustituyéndola por una serie inagotable de preguntas. Sin embargo, destaca que el ocultamiento secular del fraile, además de ser inevitable desde la precariedad expre- siva de la Historia, se debe a causas políticas, que, es necesario subrayarlo, constituyen el interés central de Arenas. Y es su descripción velada lo que comienza deshaciendo todo exclusivismo historiográfico. Aunque Arenas hubiese pretendido una refutación exclusiva del discurso historiográfico, sus palabras no dejan de transparentar la misión hermenéutica que da a la obra, contradictoria con una función meramente crítica.

\section{LA HUIDA IMPOSIBLE: FRAY SERVAN- DO Y LA HISTORICIDAD}

Así, y aparte de la incoherencia de considerar antihistoricista una obra que comienza remitiéndose a una tradición historiográfica, El mundo alucinante promete una vindicación de la figura de fray Servando en su justo lugar en la historia americana. Parecida incoherencia es la de pretender impugnar el discurso histórico, supliendo datos que la Historia es incapaz de registrar (por ejemplo el hallazgo de fray Servando del ágave mexicano en Italia, la añoranza del palmar tropical por parte de José María Heredia en las cataratas del Niágara, o el encuentro entre el dominico y el cubano), mientras «todo indica» que esos hechos debieron producirse, y querer ignorar al mismo tiempo que ese todo indicador no son sino los documentos de esa aborrecida Historia: para comenzar, la Apología y la Historia de la revolución de Nueva España de fray Servando, las biografías clásicas sobre el dominico, o Niágara de José María Heredia. De este modo, aunque la relectura de Arenas insista en una parodia de estos textos, añadiendo episodios apócrifos o simplemente grotescos e inverosímiles, asî como carnavalizando los que existen, esto no supone sino la defensa de determinada lectura de esos documentos, y por lo tanto su certificación instrumental.

La finalidad manifiesta de la novela histórica de Reinaldo Arenas, ubicar y reivindicar la figura a su juicio desatendida de fray Servando Teresa de Mier, hace que la crítica historiográfica y antihermenéutica sea parcial, y que la denuncia historiográfica nazca condicionada por la necesidad más inmediata de una «historia verdadera». La biografía paradójica y no autoritaria de fray Servando no aspira, pues, a quedarse en la crítica pura, sino a influir en una Historia sancionada por la tradición, que de este modo se refuerza indirectamente. La obra se convierte, así, en un alegato autobiográfico, como por otra 
parte el propio Arenas nunca escondió: «La novela [El mundo alucinante] es como una reconstrucción de algo que ya existe: es decir, o reconstruye un poco mi propia vida y la lleva al plano de la novela, o reconstruye una ciudad y toda una serie de personajes» ${ }^{16}$.

En este sentido, la peculiar autobiografía de El mundo alucinante, que llega a desautorizar su propia referencialidad al difuminar la unidad subjetiva de fray Servando y del autor implícito, es, sin embargo, un proyecto biográfico que desvela al mismo tiempo la conciencia ideológica que lo ha originado, tal como apunta Paul De Man en su estudio sobre el género ${ }^{17}$. De Man rebate las conocidas interpretaciones de Philippe Lejeune ${ }^{18}$, para quien la autobiografía es un modo de afirmación referencial basado en un pacto por el que el lector reconoce, a través de diversos mecanismos, la autoridad del autor y la factualidad del relato. Por el contrario, De Man observa que el género no responde a una función representacional, sino a un sistema alegórico, «a succession of voiceless tropes» ${ }^{19}$, por el que al autor implícito confiere un sentido ejemplar a ciertos hechos particulares, desfigurando el rostro real e intransferible del sujeto. El mundo alucinante parte de esta conciencia para lograr una autobiografía netamente alegórica, ejemplar y política. Así es como la alegoría, que si bien podría mitigar un recto historicismo, sirve en la novela de Arenas como síntoma de una hermenéutica histórica.

Los fines profundos de El mundo alucinante, contrarios a una mera y algo ociosa impugnación historiográfica, no la discriminan en lo sustancial de una «historia total» a través del irrealismo, que puede incluso coincidir con los conocidos planteamientos totalizadores de Georg Lukács (la ficción como Historia). Quizás a la vista de los medios y los recursos narrativos que Arenas dispone para esa finalidad historicista y política se ha querido realizar una lectura antihistoricista y postmoderna de esta novela. Pero esta apariencia de disolución nihilista no debe llevar a engaño. El descentramiento, la simultaneidad de las versiones, el absurdo, el humorismo o la recurrencia a fuentes documentales heterodoxas no tienen por qué apartarse de forma decisiva de los presupuestos de algunas corrientes historiográficas renovadoras.

Incluso la «Historia total» de los neomarxistas como Eric Hobsbawm o Josep Fontana, en su crítica a los métodos y conclusiones tradicionales del positivismo y aun del materialismo, ha estado de acuerdo en la dificultad de reducir el relato histórico a un decurso cabal, así como en la necesidad de acogerse a cierta complejidad perspectivista. Décadas antes, la escuela de Annales amplió el concepto de relato histórico a diversas corrientes que ofrecen una visión poliédrica de la realidad: la historia de las mentalidades, la historia de las costumbres, la historia de los «sin-historia» (que por fuerza desconfía del argumento documental), la historia «desde abajo", la historia de lo imaginario o las distintas «historias de los vencidos». La nowvelle histoire propugnada por Jacques Le Goff ${ }^{20}$ es, a su vez, un intento de utilizar fuentes alternativas de documentación, que, a pesar de su declarado desdén hacia los aportes de la ficción histórica, se inscribe en el proyecto de resignificación histórica al mismo tiempo que admite su propia precariedad, al centrarse con frecuencia en analizar los mecanismos de producción de los discursos.

Con estos mismos elementos de juicio, sobre todo a partir de las opiniones extraliterarias de Arenas sobre la Historia, Rodríguez Monegal tuvo, en efecto, la precaución de no calificar la novela ni el conjunto de la obra corriente de su autor como postmodernas. Por otra parte, era difícil que hacia 1965, en Cuba, Arenas pudiera estar pensando en tales categorías de análisis. Si bien esto no impide realizar una proyección postmoderna de obras anteriores al auge definitivo de dichas teorías a partir de la década de los setenta, es manifiesto, sin embargo, que las versiones postmodernizantes de El mundo alucinante no añaden diferencias sustanciales respecto a las observaciones de Monegal, sin que éste haya tenido que referirse a tales términos, que sin duda no ignoraba, ni, lo que importa, sin que haya necesitado extender la innegable crítica dialéctica de Arenas a una aporía.

Mientras que Alicia Borinsky considera que la novela de Arenas es un «juego» autorreferencial, sin posibles soluciones historicistas, y que únicamente se trata de un análisis de los mecanismos de producción de ilusiones narrativas, Rodríguez Monegal atenúa esta afirmación de la obra areniana como aporía metahistórica, al considerar que dicha intención se integra, en la práctica, y en contradicción con la teoría poética del autor cubano, en un proyecto autobiográfico. De hecho considera que el ahistoricismo señalado por la dispersión del sujeto gramatical, por la simultaneidad de versiones factuales y por la naturaleza subjetiva y paradójica del
16 Enrico Mario Santí, «Entrevista con Reinaldo Arenas», Vuelta, 47 (1980), p. 25.

17 Paul De Man, «Autobiography as De-facement», Modern Language Notes, $94: 5$ (1979), pp. 919-930.

18

Véase Philippe Lejeune, El pacto autobiográfico y otros estudios, Madrid, Megazul / Endymion, 1994

19

De Man, op. cit., p. 930.

20

Para un resumen de todas las tendencias de esta amplia corriente renovadora, véase Jacques Le Goff, Roger Chartier y Jacques Revel (directores), La nueva historia, Bilbao, Mensajero, 1988

Utopía y progreso en El mundo alucinante, de Reinaldo Arenas: Fray Servando y el tiempo histórico EDUARDO SAN JOSÉ VÁZQUEZ 
21

Véase Rodríguez Monegal, op. cit., p. 9.

22

Véase Lyotard, op. cit, pp. 2528. Lyotard trata los actos de habla como un conjunto de reglas asimilables a las de los juegos. A partir de éstas, aborda la autoconciencia contemporánea que invita al placer lúdico de actos de habla no performativos. No obstante, matiza su gratuidad significativa: «Pero, sin duda, hasta ese placer no es independiente de un sentimiento de triunfo, conseguido al menos sobre un adversario, pero de talla, la lengua establecida, la connotación»: ibid., p. 28.

23

Eduardo C. Béjar, La textualidad de Reinaldo Arenas. Juegos de la escritura postmoderna, Madrid, Playor, 1987, p. 11

24

Id.

25

lbid., p. 115

26

Véase David A. Brading, Los orígenes del nacionalismo mexicano, México, Secretariado de Educación Pública, 1973, pp. 62-63.

27

Béjar, op. cit., p. 211

28

Ibid., p. 75

Utopía y progreso en El mundo alucinante, de Reinaldo Arenas: Fray Servando y el tiempo histórico EDUARDO SAN JOSÉ VÁZQUEZ retrato de fray Servando no deja de proponer un relato progresivo. En primer lugar, por afiliarse al marco biográfico, que va desde la infancia a la muerte del protagonista; $y$, en segundo lugar, porque $E l$ mundo alucinante se alinea en paralelo a un proyecto narrativo de mayor alcance, una serie de novelas que, en número de cinco, componen la que Arenas ha denominado su «Pentagonía cubana», síntesis de los términos "pentalogía» y «agonía», compuesta por las novelas Celestino antes del alba, El palacio de las blanquísimas mofetas, Otra vez el mar, El color del verano y El asalto. Para Rodríguez Monegal, el ciclo de la «Pentagonía» forma una dilatada Bildungsroman en varios volúmenes ${ }^{21}$.

Todo lo expuesto se contradice con la tesis principal de Eduardo C. Béjar, el autor más representativo de las interpretaciones postmodernas de la obra de Arenas. Este crítico parece inspirarse en el concepto de «juego de lenguaje» desarrollado por Jean-François Lyotard $^{22}$, al considerar que en el «juego evasivo» de la obra de Arenas «América cifra otra vez su larga tradición de resistencia a la violación reduccionista del logos europeo» ${ }^{23}$. Aun obviando el violento reduccionismo de la aseveración, este análisis postmoderno de la obra de Arenas, que en el alud bibliográfico sobre el escritor cubano no deja de ser uno de los más valiosos, constituye, en abierta contradicción con «la lógica antidialéctica de nuestro presente saber» ${ }^{24}$, un prolijo centón de filosofía occidental, que por momentos parece usar la obra de Arenas como simple pretexto.

Béjar sostiene que la mayoría de la crítica precedente ha guiado su lectura areniana por códigos externos que distraían de los valores fundamentales de dichas ficciones: «su amplio campo de trabajo ha sido constreñido a la faceta de la re-escritura de la historia y de la autobiografía, o juzgada inoperante como marcadora de literaturidad de escritura por la dimensión extratextual de su pretensión ideológica» ${ }^{25}$. Por el contrario el crítico cubano defiende la dimensión exclusivamente crítica de la obra areniana, lo que denomina la «entre-textualidad» de la obra, frente a las nociones semióticas de extratextualidad e intertextualidad. Lo cierto es que Béjar podía haberse referido a la obra de Arenas en términos semejantes a los que maneja David A. Brading $^{26}$ al referirse a fray Servando. Para este historiador, la fascinación picaresca por la vida del dominico mexicano distrajo la atención sobre la originalidad de su obra y las cualidades más graves de su pensamiento histórico, político y teológico. En cierta medida, el prejuicio pintoresquista se ha adueñado también de la crítica areniana, y puede considerarse que no le faltan razones a Béjar para sostener que la biografía de Arenas ha llamado la atención de los lectores de forma desmedida, en demérito de otras aportaciones críticas y teóricas. Desde este punto de vista, Béjar cree que "Arenas busca el desmantelamiento del concepto tradicional de la obra literaria como agente logocéntrico denotativo de una verdad exterior» ${ }^{27}$. Según esto, el propósito de Arenas al escribir su novela habría sido ensayar una epistemología antiilustrada, por lo que se habría valido intencionalmente de un personaje del siglo XVIII.

Desde esta autosuficiencia literaria de la novela, el crítico intenta demostrar que las prisiones a las que se refiere El mundo alucinante serían las dialécticas, impugnando a partir de aquí cualquier interpretación autobiográfica $\mathrm{y}$, en definitiva, política o histórica. Lo cierto es que la lectura de Béjar no deja de ser sugestiva y, en razón de sus propias expectativas, inobjetable. El crítico cubano propone considerar que la sucesión potencialmente infinita de prisiones y fugas del protagonista de El mundo alucinante compone una alegoría de la pulsión antidialéctica de Arenas, tratando de superar los códigos del binarismo y de la objetividad mimética. El propio fray Servando no tendría otro significado que el de «figura» y «palabra»; su función en la novela estaría determinada por su carácter de escritor, y le serviría a Arenas para la problematización de la literatura política de Hispanoamérica. De esta manera, convertida la novela en «teatro de la escritura» ${ }^{28}$, todos sus elementos actanciales son símbolos diegéticos. Por ejemplo, las ratas que infestan la celda de fray Servando en Las Caldas de Santander serían las letras que devoran el espacio textual, formas del pensamiento dialéctico, en oposición a las «dos o tres hormigas locas» (p. 91) que cruzan por el techo, en las que se reconocerían las ideas libres del fraile. En los últimos capítulos, la búsqueda de un encuentro trascendente con la divinidad por parte de fray Servando, imposible desde la prisión normativa del logos, es, para Béjar, una mística del conocimiento humano.

Así, ante la vista de la procesión de Guadalupe desde el Palacio Nacional, Heredia conmina al fraile: «hay que romper este 
encantamiento engañoso» (p. 296). La idolatría mariana, que fray Servando comienza a despreciar después de haber sufrido prisiones por defender el culto guadalupano, es, así, el símbolo de la estafa de los significantes, frente a una genuina mística del conocimiento. La lucha utópica del fraile se reduce, a su vez, a la crítica antidialéctica y al impulso irracional de trascender la prisiones expresivas. Así cuando el fraile protesta: « $i S e r v i r$ a esa chusma brutal que todo lo reduce a esquemas?» (p. 294). Fray Servando siente, al mismo tiempo, que la plenitud del paraíso, símbolo de la inteligencia absoluta para Béjar, es improbable: «Y, ¿̇realmente, estamos en el paraíso? ¿Y, realmente [...] existe tal paraíso?» (p. 295). Al final, el protagonista sentiría que sólo la muerte puede liberarlo de la estafa dialéctica:

Y de golpe, oyendo aquel escándalo que volvía a enloquecerlo, presintió que durante toda su vida había sido estafado. [...] Entonces tuvo la revelación. Pensó que el objetivo de toda civilización (de toda revolución, de toda lucha, de todo propósito) era alcanzar la perfección de las constelaciones, su armonía inalterable (p. 303).

Fray Servando, sin embargo, llega a considerar que su empeño es imposible: «Pero jamás — dijo en voz alta-, llegaremos a tal perfección, porque seguramente existe algún desequilibrio» (p. 304). En pleno trance místico de fray Servando, Arenas opone, en una antítesis de raíz platónica (filosofía/ poesía), el desconcierto de Heredia ante el comportamiento enajenado del fraile. Mientras, el poeta, representante de la logomaquia y el fraude expresivo, contempla atónito el trance del fraile, éste percibe que se aproxima al núcleo ontológico ajeno a la Historia, una bola de fuego:

Y ya iba a desprenderse a otros sitios remotos, a habitar un tiempo donde no existía la memoria, sólo un presente despoblado. El principio, la revelación:

-Dios - dijo entonces-. Voy hacia Dios.

Y ya se impulsaba, y ya alzaba los brazos. Pero el gran escalofrío [...] lo recorrió de nuevo. Y el fraile dudó. Y sintió miedo. Miedo de que al final de aquellos vastos recintos no hubiese nadie esperándolo. Miedo a quedarse flotando en un vacío infinito, girando por un tiempo despoblado, por una soledad inalterable donde ni siquiera existiría el consuelo de la fe (p. 304).

Al final, consigue sacarlo del trance el ruido de las campanas, repetido aliterativamente en las dos páginas siguientes mediante el sintagma «campanas, campanas», recurso con el que la narración consigue que el ritmo y los significantes fónicos obliteren el significado, subrayando la recaída del protagonista en la engañosas apariencias del logos. Fray Servando se ha resignado a sus momentos más críticos de duda: «Es que no hay salida. Es como si a cada momento fuera enterándome de lo inútil de esas huidas» (p. 122). En definitiva, para Béjar, fray Servando ha llegado a la conclusión de que el sistema dialéctico y el historicismo causal componen los elementos discursivos de que se nutre su propia rebelión antidialéctica: «¿Para qué quieres modificar lo que precisamente te forma?... No creo que seas tan tonto como pensar que existe alguna manera de liberarte» (p. 95). En general, es extraño que el crítico ignore, de acuerdo a esta misma solución dentro de su esquema interpretativo, el desfase entre la teoría disgregadora de Arenas y la práctica irremediablemente historicista en que, consecuentemente, recae la novela.

En una línea de interpretaciones semejante, Alejandro Herrero-Olaizola ha considerado que El mundo alucinante desvirtúa cualquier tipo de conocimiento histórico, asimilando éste a la ficción, en una progresiva «quijotización» de fray Servando. Fruto de la alternancia indistinta de Historia y literatura, la novela «no aspira a «contar la verdad» o a establecer cómo llegar a ésta, sino más a bien a cuestionar (a través de la parodia) la verdad que se cuenta» ${ }^{29}$. En otro estudio, HerreroOlaizola $^{30}$ subraya que el propósito de esta novela es vetar la posibilidad del conocimiento histórico desde la imposibilidad de rastrear un referente. $\mathrm{La}$ inexactitud del discurso comenzaría en el intento de establecer la genética bibliográfica de El mundo alucinante, que llevaría a la primera edición en francés de 1968, previa a la primera edición española de 1969, con el título Le monde ballucinant. Así, la edición príncipe de la novela se trata ya de una traducción del manuscrito original, que más adelante sería revisado por el autor y publicado en español como texto «original» ${ }^{31}$. Esta dispersión de los originales señalaría la imposibilidad de cualquier acercamiento histórico, que se evidencia en la parodia de los materiales del licenciado Borunda que sirvieron a fray Servando para componer su versión de la leyenda de Guadalupe, y se refuerza con la reducción al absurdo de las fuentes biográficas sobre el fraile, o con su contaminación con textos ficcionales, como Orlando, de Virginia Woolf.
29

Alejandro Herrero-Olaizola, "Las alucinantes peregrinaciones de Fray Servando en El mundo alucinante de Reinaldo Arenas», en Narrativas híbridas: Parodia y postmodernismo en la ficción contemporánea de las Américas, Madrid, Verbum, 2000, p. 65.

30

Alejandro Herrero-Olaizola, «EI mundo alucinante o el «postmodernismo» de Reinaldo Arenas: visiones y re-visiones paródicas de la historia de fray Servando", Symposium. A Quaterly Journa in Modern Foreign Literatures, 48:2 (1994), pp. 120-134.

31

En 1967, refiriéndose a su propia novela, premiada en el concurso de novela de la UNEAC en 1966, pero aún inédita, Arenas ya declaraba haberla cambiado mucho respecto a original a concurso, e incluso llegó a pensar en cambiarle el título. Ette, op. cit., p. 99.

Utopía y progreso en El mundo alucinante, de Reinaldo Arenas: Fray Servando y el tiempo histórico EDUARDO SAN JOSÉ VÁZQUEZ 
32

Ibid., p. 98

33

Hobsbawm, op. cit., p. 199

En este capítulo dedicado a la

historiografía postmoderna, con-

sidera que esa verificabilidad

«no puede ni siquiera evitar

totalmente la terrible acusación

de «positivismo»» (id).

\section{4}

Véase Linda Hutcheon, A Theory of Parody. The Teaching of Twentieth-Century Art Forms, New York, Methuen, 1985, pp. 2829.

35

El término es de Fernando Ainsa, para referirse a la deconstrucción paródica y humorística que la ficción histórica reciente hace de los referentes históricos (Ainsa, op. cit., p. 16).

36

Véase René Jara, "Aspectos de la intertextualidad en El mundo alucinante», Texto Crítico, 13:5 (1979), pp. 219-235.

37

Volek, op. cit., p. 147.

38

Ibid., p. 138

39

Elzbieta Sklodowska, «El mundo alucinante: historia y ficción» en Hernández Miyares y Rozencvaig (eds.), op. cit., p. 159

40

Andrea Pagni, «Palabra y subversión en El mundo alucinante», en Ette (ed.), op. cit., pp. $139-148$

41

Eduardo G. González, «A razón de santo: últimos lances de fray Servando», Revista Iberoamericana, 92-93:41 (1975), pp. 593-603.

Utopía y progreso en El mundo alucinante, de Reinaldo Arenas: Fray Servando y el tiempo histórico EDUARDO SAN JOSÉ VÁZQUEZ

\section{EL TIEMPO DEL RELATO Y EL TIEM- PO HISTÓRICO}

La circularidad y la inmanencia del tiempo, que sustituyen a la noción progresiva de la Historia como patrón organizativo de la ficción histórica de Arenas, ha sido uno de los argumentos más invocados para señalar esa postmoderna imposibilidad, que indicaría la impugnación de la idea ilustrada de progreso. Pero, como ya se ha apuntado, Rodríguez Monegal observa que si, por un lado, la estructura cíclica y fatalista que sugiere la articulación de las acciones de fray Servando en una dinámica reiterativa de fuga y prisión apunta una concepción cíclica de lo histórico, por otro lado, la pertenencia de la novela al género de la (auto)biografía implica una sucesión lineal, en la que la muerte propicia la liberación postrera del fraile. No obstante, se debe replicar parcialmente a esta idea con el «viaje a la semilla» que supone el relato de Arenas. El fraile, en el momento de morir, regresa a su infancia, cerrando el progreso de la narración sobre sí misma: «Y luego volviste a Monterrey, pues ya eras un muchacho. Y emprendiste el regreso a la casa, desde el corojal» (p. 311). Además, el capítulo añadido a modo de epílogo, «Últimas noticias de fray Servando», cuenta los avatares humillantes del cadáver, cuya momia terminó exhibida «como una víctima de la inquisición» en un circo belga, con lo que el narrador aclara que «realmente, sus restos no alcanzaron el merecido reposo» (313). En este sentido, Ottmar Ette cree que Arenas combina en la novela los dos esquemas temporales, el circular y el progresivo, para afirmar que «en otras palabras, no borra la Historia sino refuta su omnipotencia» ${ }^{32}$.

Pero el biografismo que señala Rodríguez Monegal para contradecir su eventual aporía no es lo que separa El mundo alucinante de una absoluta refutación de las nociones históricas. Tampoco lo es el innegable debate historicista que se proyecta sobre la tradición metodológica: en primer lugar al pretender situar la propia novela tras ciertas formas discursivas de la novela histórica y de la historiografía, y, en segundo lugar, por respetar la característica que Eric Hobsbawm defiende para cualquier intento de conocimiento: la verificabilidad ${ }^{33}$, que en este caso se produce en el ámbito de los debates metodológicos. Este tipo de crítica del historicismo es, para Linda Hutcheon, la única índole representacional que cabría considerarse en las ficciones postmodernas, conjurando su riesgo de «nihilismo aristocrático» con el carácter político de la crítica a la tradición discursiva ${ }^{34}$.

¿Cómo responde, entonces, el entramado novelesco de Arenas a la incitante llamada del sentido histórico? A pesar de su parodia a los recursos de fijación de la verdad histórica, es imposible ignorar que la crítica epistémica de Arenas necesita demostrar una lectura histórica concreta en la que poder justificarse y verificarse. Se debe tener en cuenta, fundamentalmente, que fray Servando Teresa de Mier fue un polemista, perfil que deja su escritura muy alejada de la aporía, y como tal lo presenta la novela, sin que el autor evite reflejarse en él. A pesar de la «derrisión» 35 que opera el narrador sobre la figura del fraile, sobre su unidad como sujeto y sobre las razones históricas que aparecen en sus escritos, Arenas ha necesitado documentar una versión histórica sobre la que justificar el hartazgo epistemológico.

Sin embargo, varios críticos han huido de las lecturas más limitadamente metahistóricas. De este modo, René Jara ${ }^{36}$ y Emil Volek consideran que la novela no alcanza el ludismo antimimético que dejaría sugerir la intención de estos recursos. Volek considera que, a causa de su referencialidad que no deja de proyectar a través de la alegoría, El mundo alucinante es una obra fallida. Cree que la obra «fracasa [...] por abandonar la imaginación carnavalesca por un mensaje directo [...] cuyo vehículo es la gastada alegoría tradicional [...]. Resulta una obra neovanguardista a medio hacer» ${ }^{37}$. La tesis de Volek saca a la luz los códigos contextuales diseminados en la novela, y es la única que pone en una relación de directa necesidad la estética irrealista de la obra con su contexto real. La explicación es tan sencilla como evidente. Los procedimientos desrealizadores de la novela «[sirven] tal vez de una hoja de parra para protegerse de la ira de los nuevos césares» ${ }^{38}$.

Elzbieta Sklodowska considera que El mundo alucinante propone una enajenación brechtiana que impide toda identificación del lector con el texto, a pesar de lo cual éste «no desemboca en un nihilismo en cuanto al progreso histórico» ${ }^{39}$. Andrea $\mathrm{Pagni}^{40}$ apunta la doble dirección connotativa de la obra: en cuanto a los modos de narrar, dirigiéndose contra Carpentier; y en el plano autobiográfico y apologético, lleno de alusiones reales. Por último, Eduardo G. González ${ }^{41}$, quien llega a comparar las características esenciales y menos aparentes de la obra areniana con la épica de Victor Hugo, interpreta que la pulsión mística del protagonista inscribe a 
Arenas en la tradición romántica, en un final o desdoble irónico de la misma, que aborda la inserción del individuo en el contexto histórico, su búsqueda de identificación y plenitud, y los conflictos existenciales de sentir el propio ser en desequilibrio con la época.

Un pasaje de la novela desvela que Arenas no ha pretendido alejarse de la razón, y en particular de las razones históricas, mostrando una actitud, al contrario, ideológica y lascasiana. En varias ocasiones, Arenas se refirió a la necesidad de recuperar el discurso histórico de las manos de los vencedores ${ }^{42}$. En el momento en que el perseguidor de fray Servando, Francisco Antonio León, le tiende una trampa en la que captura al fraile, éste proclama: «He sido ofendido, y todo no ha sido más que por decir lo que honestamente entendía y pensaba. He sido desterrado de mi patria y vilipendiado, solamente porque quise que la verdad ocupase su lugar» (p. 139); pero su perseguidor termina aconsejándole: «lo que más se debe ocultar es la razón, pues casi nunca nos sirve para nada, y solamente es arma de los vencidos» (p. 142). A pesar de ello y de verse capturado de nuevo a causa de su ingenuidad y de la obstinada argumentación de sus razones, sin la que probablemente ya estaría libre, el fraile no se deja vencer por el punto de vista de León. Al contrario, continúa con sus alegaciones y escritos, de los que la propia novela de Arenas se extiende como un episodio apologético más. Así, en el coloquio que fray Servando sostendrá en México con Iturbide, el fraile le replica al emperador recién coronado: «-No pretendo obtener ningún éxito si no es a través de la razón. Para serle franco y andar sin ambages, señor Agustin, lo que usted ha hecho no es más que un puro fraude...» (p. 270; la cursiva es del texto). En un sentido que se puede aplicar ahora, Julio Ortega se ha referido al «espacio liberado» ${ }^{43}$ de una historiografía hispanoamericana propia, representada en las reescrituras paródicas de la nueva narrativa histórica frente a la Historia oficial. Tratar de ocultar la dimensión connotativa e historicista de esta narrativa y de la obra de Arenas bajo la exclusividad de lo metahistórico significa olvidar los matices de ese espacio de la Historia que ya no estaría, pues, liberado, sino «desocupado». Un relativismo que la vida y la obra de Arenas no dan lugar a ofrecer.

Por eso, aparte del Sermón de Guadalupe, el otro nudo discursivo, entre los escritos del padre Mier, que desarrolla la novela es la llamada Profecía, en la que Mier advertía al
Congreso Constituyente mexicano de 1823 de los peligros de los modelos inglés y estadounidense y de un federalismo para el que los mexicanos no estaban preparados: "Yo siempre he estado por la federación, pero una federación razonable y moderada, una federación conveniente a nuestra poca ilustración y a las circunstancias de una guerra inminente, que debe hallarnos unidos» (p. 275 $)^{44}$. El mundo alucinante muestra a un Mier, que, al igual que Bolívar, y al igual que Arenas, había dado su ilusión a un ideario liberador y utópico que con el tiempo comienzan a trocar en un posibilismo político. El Bolívar que avisaba al congreso de Angostura de que «cuanto más admiro la excelencia de la Constitución Federal de Venezuela, tanto más me persuado de la imposibilidad de su aplicación a nuestro estado» ${ }^{45}$, federalismo en el que no dejaba de predecir «la muerte del gobierno, cuyos herederos son la anarquía, la usurpación y la tiranía ${ }^{46}$, podría ser el mismo Mier que comenzaba defendiéndose «¿se podrá dudar de mi republicanismo? [...]; yo también fui jacobino» ${ }^{47}$, recordando su pasada oposición al Plan de Iguala y a los Tratados de Córdoba y reafirmando la independencia como única solución digna, para concluir, sin embargo, que «querer desde el primer ensayo de la libertad remontar hasta la cima de la perfección social es la locura de un niño que intentase hacerse un hombre perfecto en un día» ${ }^{48}$. Asimismo, «el pueblo siempre ha sido víctima de la seducción de los demagogos turbulentos, y su voluntad numérica es un fanal muy oscuro ${ }^{49}$. Por eso, busca esa «nación sensata [que] no gusta de principios generales ni máximas abstractas, porque son impertinentes para el gobierno del pueblo» ${ }^{50}$.

La certeza de que la tradición nacional es un artificio de canonistas descreídos no le sirve a Arenas para impugnar la factualidad y desmontar toda posible historia, sino para limitar los alcances de ambas, y ofrecer una precisa versión histórica de los problemas políticos de Hispanoamérica. Es más esclarecedor de los sentidos de El mundo alucinante apartarse de la lectura estrictamente crítica y antihermenéutica, que considera, como ha hecho Eduardo C. Béjar, que la mística y el «paraíso» cuya búsqueda define el tránsito vital de fray Servando en la novela responden a una pulsión antidialéctica. Por el contrario, esa pulsión se aviene a la lucha contra el dogmatismo que caracterizó la pugna historiográfica del fraile, y se manifiesta en la obra con una estética vanguardista que, asimismo,
42

Véase Pagni, op. cit., p. 145.

43

Julio Ortega, El discurso de la abundancia, Caracas, Monte Ávila, 1992, p. 78.

44

La cita es literal, de la Profecía del doctor Mier sobre la

federación mexicana, en Fray Servando Teresa de Mier, Ideario político (prólogo, notas y cronología de Edmundo O'Gorman) Caracas, Biblioteca Ayacucho, 1978 , p. 294

45

Simón Bolívar, "Discurso de Angostura», en Doctrina del libertador (prólogo de Augusto Mijares, compilación, notas y cronología de Manuel Pérez Vila), Caracas, Biblioteca Ayacucho, 1976, p. 108.

46 Ibid., p. 118

47 Mier, op. cit., pp. 289 y 293.

48

Ibid., p. 290

49 Ibid., p. 292 50 Ibid., p. 297.

Utopía y progreso en El mundo alucinante, de Reinaldo Arenas: Fray Servando y el tiempo histórico EDUARDO SAN JOSÉ VÁZQUEZ 
51

Octavio Paz, Los hijos del limo. Del romanticismo a la vanguardia, Barcelona, Seix Barral, 1974 , p. 78.

\section{2}

Para una noticia de los periplos de prófugo de Arenas hasta su detención en el Parque Lenin de La Habana, véase Juan Abreu, A la sombra del mar. Jornadas cubanas con Reinaldo Arenas, Barcelona, Casiopea, 1998. Los hermanos Abreu fueron testigos y protagonistas de esos días, de los que se extrae este recuento aún más detallado que el de la autobiografía areniana. Es interesante, con todo, destacar las ocasiones en que compara la odisea areniana con $\mathrm{El}$ mundo alucinante. Véanse pp. 49, 61, 67,79 y 178

53

Luis Villoro, El proceso ideológico de la revolución de Independencia, México, Secretaría de Educación Pública, 1986, p. 234.

54

Véase Eduardo San José Vázquez, «Evolución e importancia del pensamiento histórico de fray Servando Teresa de Mier», Cuadernos de Estudios del Siglo XVIII (Universidad de Oviedo), 15 (2005), pp. 209-232.

55

Jacques Le Goff, El orden de la memoria. El tiempo como imaginario, Barcelona, Paidós, 1991.

56

José Antonio Maravall, «El pensamiento utópico y el dinamismo de la historia europea», en José Antonio Maravall et. al., La utopía y las utopías, Madrid, Asociación Cultural Hispano-Norteamericana, 1976, p. 18. obedece en parte a la autocensura y el exilio interior de su autor. La lucha del Mier histórico contra los conceptos absolutos, así como el significado más plausible de ese "paraíso", deben reubicarse en la intención política del personaje que se queja « ¿ esto es el fin? ¿Esta hipocresía constante, este constante repetir que estamos en el paraíso y que todo es perfecto?» (págs. 294-295). Una queja que alude a las utopías del siglo y que constituye una reivindicación formal de la Historia y del progreso, en todo cuanto éste se opone a la utopía perfecta.

La supuesta postmodernidad de la obra de Arenas no sería, pues, objetable si no implicara una rígida exclusión de cualquier valor historicista. En su lugar, es preferible atender a las definiciones que muchos autores han hecho de la modernidad, como un concepto cuyo sentido original nace ya de la negación y la crítica, y que encuentra en la razón su potencialidad autodisolvente. Octavio Paz ha observado varios de estos momentos antimodernos de la modernidad, que para el autor mexicano pueden representarse idealmente en la tendencia romántica de crítica a la modernidad ilustrada y utópico-revolucionaria. Frente a ésta, y al igual que las obras de Mier y Arenas, la literatura romántica «es revolucionaria no con sino frente a las revoluciones del siglo» ${ }^{51}$. De acuerdo con Eduardo G. González, sitúo la obra de Arenas en una perspectiva, pues, más amplia, dentro de una temática típicamente romántica, que es una invitación a la Historia frente a la utopía nacida de los sueños de la razón.

\section{LA REVOLUCIÓN DESDICHADA: UTOPÍA Y PROGRESO}

Lo afirmado hasta aquí se resume en un rescate de la figura del padre Mier desde un punto de vista que, en definitiva, poco tiene que ver con un estrecho autobiografismo. Sería imposible que Arenas pudiera realizar tal identificación metafórica en 1965, cuando escribe la novela. Los avatares de persecución y exilio que podían vincular al autor con el protagonista de su novela aún no habían te- nido lugar, ya que su primer encausamiento data de 197452 . Y, sobre todo, la crítica general que, entonces, anima esta obra tiene su objeto en una idea de utopía en cuyo debate debería situar el lector las citas de la novela entresacadas para este artículo. El mencionado «fraude» de los esquemas dialécticos transparenta, en estas ocasiones, la arrogancia absolutista de ciertas ideas frente a la tradición y la experiencia. Una idea cartesiana de la utopía contra la que el padre Mier empleó sus últimos esfuerzos ante los constituyentes mexicanos, pretendiendo asentar una noción ilustrada del pensamiento utópico vinculada eminentemente a la experiencia.

De este modo, Arenas se propuso un alegato de la figura del padre Mier que los historiadores contemporáneos tardaron en alcanzar, llevados antes del influjo picaresco de su biografía. Así, Arenas coincide en las apreciaciones de Luis Villoro, para quien la Profecía puede considerarse como el primer planteamiento mexicano del tema de la «revolución desdichada» ${ }^{53}$. La atención de Arenas se concentra en la invitación de Mier a un «federalismo templado», que debe traducirse como una propuesta de soluciones conciliadoras dentro de un posibilismo político «conveniente a nuestra poca ilustración» (p. 275). Desde este mismo punto de vista, la figura de Mier se ha revaluado hoy gracias a las observaciones de historiadores como Edmundo O'Gorman, André Pons, André Saint-Lu o David A. Brading, quienes aprecian la influencia final de Mier en el posibilismo de Bolívar, Blanco White o varios de los constitucionalistas mexicanos ${ }^{54}$. La idea ilustrada del dominico, como la de Arenas, a propósito de la utopía se aparta de una pretendida postmodernidad, para situarse con las observaciones de autores como Jaques Le Goff ${ }^{55}$ o José Antonio Maravall acerca de la verdadera utopía, como aquélla que huye de una formulación o localización (u-topos) precisa y restringida, para afirmarse en un deseo permanente de mejora: aquel impulso (si se quiere aquí, místico) por el cual «no se planifica la libertad, sino que se planifica para la libertad» ${ }^{56}$. 